\title{
HABERMAS E LYOTARD: UM DEBATE SOBRE A PÓS-MODERNIDADE
}

\author{
HABERMAS AND LYOTARD: A DEBATE ON POST-MODERNITY
}

\author{
ANDRÉ HENRIQUE M.V. DE OLIVEIRA \\ PROFESSOR DE FILOSOFIA DO IFPI
}

\begin{abstract}
RESUMO: Em nosso trabalho procuraremos apresentar os traços principais do livro de Lyotard, $A$ condição pós-moderna, para em seguida analisarmos um dos ensaios de Jürgen Habermas no livro Técnica e Ciência como Ideologia, a fim de identificarmos como o filósofo alemão trata da mesma questão e propõe uma alternativa frente a dominação da razão instrumental da tecnociência.
\end{abstract}

Palavras-chave: Ciência; Ideologia; Pós-modernidade; Técnica.

\begin{abstract}
In our work we try to present the main features of the book of Lyotard, The postmodern condition, then look for one of the essays by Jürgen Habermas in this book Technique and Science as Ideology, in order to identify how the german philosopher deals with the same issue and proposes an alternative before the domination of instrumental-reason of techno-science.
\end{abstract}

Key-words: Science; Ideology; Postmodernism; Technical.

\section{INTRODUÇÃO}

Um dos temas que mais tem marcado o debate filosófico contemporâneo refere-se à controversa denominação de nossa época como "pós-moderna”. Não há ainda consenso sobre que características demarcariam precisamente essa "nova" cultura. No entanto, uma ideia aceita de modo mais pacífico é a de que a tecnociência estaria incorporada em nossa sociedade como nunca havia estado, de modo que a própria técnica e sua aplicação na ciência figuram como subitens no debate sobre pós-modernidade.

Vários pensadores têm participado desse debate, alguns adotando posições que levantam polêmicas a esse respeito, outros de modo mais distanciado, apenas ressaltando seu ponto de vista sobre o que seria a "pós-modernidade".

Uma obra que alcançou notável relevância no interior desse debate foi $A$ condição pós moderna, de Jean-François Lyotard, na qual o filósofo apresenta a mudança no estatuto e na legitimação do saber como uma marca essencial da pós-modernidade. Em nosso trabalho procuraremos apresentar os traços principais do livro de Lyotard, para em seguida analisarmos um dos ensaios de Jürgen Habermas no livro Técnica e Ciência como Ideologia, a fim de identificarmos como o filósofo 
alemão trata da mesma questão e propõe uma alternativa frente a dominação da razão instrumental da tecno-ciência.

\section{LYOTARD E A CONDIÇÃO PÓS-MODERNA}

Em linhas gerais, podemos dizer que o trabalho desenvolvido por Lyotard em $A$ condição pós-moderna possui um caráter predominantemente diagnóstico, pois qualquer vestígio de proselitismo é ofuscado pelo forte apelo descritivo com o qual se reveste sua análise. O objetivo do seu estudo é traçar uma análise criticamente descritiva de uma condição, isto é, da condição "pós-moderna", entendida como um momento histórico que teria assumido características particulares frente a uma outra condição que poderíamos chamar de "moderna".

A análise que Lyotard faz desta nova condição não se dá ao acaso nem parte do vazio, ao invés disso toma como ponto de partida concreto a posição do saber nas sociedades mais desenvolvidas. Lyotard investiga o estatuto e as relações que o saber estabelece com a sociedade dentro da qual ele é produzido, revelando as implicações de ordem estratégica e de ordem política que tal relação comporta.

O próprio sumário do livro sintetiza de maneira clara e pontual o campo onde se dará a investigação (o saber nas sociedades informatizadas); o problema que é levantado (a legitimação); e o método de abordagem (os jogos de linguagem). Com base nisso, não há risco em afirmarmos que o que lemos em $A$ condição pós-moderna é uma análise das bases que legitimam a produção e a transmissão do saber nas sociedades informatizadas. Trata-se assim de um tema que nos introduz no âmbito da pesquisa científica e da sua reverberação através das diversas instituições de ensino, que intercediam a relação da ciência com o tecido social.

No decorrer do texto, Lyotard passa a detalhar e contrapor em cada seção as características da perspectiva moderna e pós-moderna no que se refere aos seus modos de pesquisa, legitimação, vínculo social, e aspectos pragmáticos do saber.

A questão da legitimação do saber científico ocupa um lugar central na discussão, porquanto começa a apontar para uma nova configuração do discurso científico, ou mais precisamente para as novas condições e exigências às quais deve atender a pesquisa científica. Assim, também o que a ciência produz passa a ser direcionado por essa nova "medida". A estreita relação que se observa entre o saber, as novas tecnologias e as potências que as dominam leva Lyotard a 
adiantar que "o problema do saber na idade da informática é mais do que nunca o problema do governo" (LYOTARD, 2009).

A sociedade que comporta a nova configuração do saber, com seus jogos (lances) de linguagem, não atende aos modelos modernos de vínculo social, ou seja; ela não é mais representada como um sistema orgânico e funcional que visava apenas sua auto-regulação, nem como mecanismo que tenha como motor a luta de classes. A "máquina social” pós-moderna tem sim como princípio motor a otimização de suas performances; sua preocupação é com a melhora do desempenho, isto por que nas sociedades informatizadas a classe que detém o poder:

\footnotetext{
já não é mais constituída pela classe política tradicional, mas por uma camada formada por dirigentes de empresas, altos funcionários, dirigentes de grandes órgãos profissionais, sindicais, políticos, confessionais (Ibidem).
}

Passamos a viver numa sociedade de experts, que operacionalizam os mais diversos segmentos, inclusive o da esfera política que sustenta e exige da pesquisa o atendimento de suas estratégias de desempenho.

Uma vez traçada a representação de sociedade na condição pós-moderna, Lyotard retoma o problema da legitimação analisando a pragmática do saber narrativo, que constituiu o saber tradicional, e a pragmática do saber científico, a partir de seu isolamento num jogo de linguagem específico. O filósofo identifica dois grandes relatos (ou metarrelatos) que legitimavam o saber moderno e suas instituições: um que justificava o saber em função da liberdade e emancipação da humanidade, legitimando o saber pela sua suposta força de transformação política, e o outro para o qual o sujeito do saber seria o Espírito especulativo; o saber se legitimaria a si mesmo na medida em que ele, enquanto sistema absoluto, explicaria a função de todas as coisas no percurso do Espírito.

A mudança que vem se operando nos últimos tempos engendrou a decadência dessas formas de legitimação. Os "germes de deslegitimação" já estariam latentes, segundo Lyotard, nos próprios relatos do século XIX: no relato especulativo na medida em que encerra um certo "ceticismo" em relação ao conhecimento positivo, e no relato de emancipação, por haver nele o sério problema da incongruência entre enunciados denotativos e enunciados prescritivos, isto é, enunciados que almejam um alcance prático. Em outros termos, o relato de emancipação carrega a dificuldade de estabelecer uma implicação consistente entre o "verdadeiro" e o "justo". Desse modo: 
$\mathrm{Na}$ sociedade contemporânea e na cultura contemporânea, sociedade pós-industrial, cultura pós-moderna, a questão da legitimação do saber coloca-se em outros termos. O grande relato perdeu sua credibilidade, seja qual for o modo de unificação que lhe é conferido: relato especulativo, relato de emancipação. (LYOTARD, 2009)

O critério de legitimação que agora se impõe é o do desempenho, tanto no que se refere à pesquisa quanto ao ensino. Nesse contexto, a técnica aparece como elemento fundamental para a otimização das performances e administração das provas que sustentam qualquer argumentação científica. Sua utilização, todavia, exige um dispendioso investimento. Assim, "nada de prova e de verificação de enunciados, e nada de verdade, sem dinheiro" (LYOTARD, 2009). Lembrando que a fonte dos financiamentos pertence a "homens de negócio" cujo interesse é, antes da verdade, o poder. $\mathrm{Na}$ era da legitimação pelo desempenho a ciência torna-se uma variável numa equação financeira.

Do mesmo modo, o ensino não deve se ocupar com o verdadeiro/falso, justo/injusto, mas com o eficiente/ineficiente. $O$ ensino superior não tem como função formar ideais, mas competências que venham a melhorar o desempenho do sistema social.

Vista do que se pode considerar uma perspectiva mais internalista, a ciência pós-moderna revela seu caráter de instabilidade pelo modo de trabalhar com base em "paradoxos" e "contraexemplos", forçando assim uma constante alteração nas regras que compõem seus jogos de linguagem: uma espécie de descontinuidade que, em certa medida alimenta o parâmetro da legitimação pelo desempenho.

Este modelo paralógico e de instabilidade que caracteriza a ciência pós-moderna deixa em aberto a configuração do cenário internacional no que se refere à relação entre economia, ciência e poder. Isto por que, segundo a análise de Lyotard, "o consenso tornou-se um valor ultrapassado". $\mathrm{Na}$ condição pós-moderna a ciência e a sociedade não possuem uma "metalíngua geral na qual todas as outras podem ser transcritas e avaliadas".

Essas são as conclusões alcançadas por Lyotard. Sem qualquer pretensão de prescrever uma nova ordem ou regras alternativas, seu trabalho mantém-se no nível da descrição, ainda que seja uma descrição com olhar crítico. Isso torna o texto de Lyotard uma boa referência para o debate contemporâneo, independentemente da terminologia com que se nomeie nosso tempo ("hipermodernidade", "modernidade líquida", etc.).

Para além dos rótulos, Lyotard consegue tornar visíveis os elementos e as relações que compõem o cenário contemporâneo; os bastidores silenciosos aonde entram em acordo ciência, 
tecnologia e poder. Sem arriscar um olhar pessimista ou mesmo catastrófico, tal como se observa nos teóricos de Frankfurt, Lyotard ainda rebate de maneira sutil a tese de Habermas ao diminuir a força que este credita ao "consenso".

\section{HABERMAS: TÉCNICA E CIÊNCIA COMO IDEOLOGIA}

No texto "Técnica e Ciência como Ideologia”, Habermas estabelece um diálogo crítico com Marcuse a respeito do progresso técnico-científico e da conseqüente institucionalização da técnica e da ciência no seio da sociedade contemporânea. Indiretamente, Max Weber é chamado à discussão, já que Marcuse discute o conceito de "racionalidade" tal como Weber o concebeu. As idéias que Habermas desenvolve nesse ensaio atingem de forma direta a concepção de Marcuse, e de forma indireta a tese de Max Weber.

Para Weber, a forma de atividade econômica predominante no capitalismo seria produto de uma "racionalidade", na medida em que as esferas sociais estariam submetidas a critérios de decisão racional. As decisões tomadas em larga escala visam à organização dos meios e a realização dos fins, sendo que tal processo passa a depender cada vez mais da institucionalização do progresso científico.

$\mathrm{Na}$ visão de Herbert Marcuse, a "racionalidade" pensada por Weber se restringe às ações características do modelo capitalista de trabalho (o empresariado capitalista, o trabalhador industrial, o funcionário moderno, etc.) Este "racionalização" de fato comporta critérios da técnica e da ciência, no entanto, isto não nos autoriza dizer que assim se implante a "racionalidade" como tal. Para Marcuse, tal processo ocultaria em seu interior uma forma de dominação política. A "racionalidade" de Weber, na medida em que se refere ao emprego de estratégias que se adequem à utilização de tecnologias e a realização de fins "práticos", implicaria uma forma de dominação: um exercício de controle seria efetivado ou sobre a natureza, ou sobre a própria sociedade.

Uma vez que, "a razão técnica de um sistema social de ação racional dirigida a fins não abandona o seu conteúdo político" (HABERMAS, 1968), aquela "racionalidade", em nome da racionalidade, perfaz a institucionalização de uma dominação, uma dominação amparada na técnica e na ciência. Marcuse afirma mesmo que:

Determinados fins e interesses da dominação não são outorgados à técnica apenas 'posteriormente' e a partir de fora - inserem-se já na própria construção do aparelho técnico; a técnica é, em cada caso, um projeto histórico social; nele se projeta o que uma 
sociedade e os interesses nela dominantes pensam fazer com os homens e com as coisas. (HABERMAS, 1968)

Esta "razão" técnica, seria, portanto, ideologia, uma vez que se encontra presente não só no plano material, mas também no modo de se pensar uma organização social e política, donde advêm os interesses e as ações dos indivíduos. Enquanto ideologia, essa "racionalidade" seria uma base de legitimação implícita no modo como se estruturam as relações de produção e o aparelho de dominação política, agora também técnico e científico.

Marcuse revela assim um certo conteúdo político no interior da razão técnica. Diante desta análise, Habermas se questiona sobre a possibilidade de emancipação num contexto em que a dominação se funde com a técnica, e é ela mesma técnica. Dado que esse novo perfil da sociedade capitalista se formou sob dependência do progresso técnico-científico, poderíamos supor como condição para a libertação desse paradigma ideológico uma revolução na técnica e na ciência, ou seja, a técnica e a ciência precisariam ser reformuladas para que se pudesse projetar um modelo alternativo de organização sócio-política. Uma outra "técnica" permitiria, talvez, uma atitude diferente em relação à sociedade e à natureza.

Nesse ponto da discussão Habermas atenta para a tese de Arnold Gehlen. Para este há uma "conexão imanente entre a técnica que conhecemos e a estrutura da ação racional dirigida a fins" (HABERMAS, 1968). A técnica seria uma manifestação direta, um resultado característico da ação racional teleológica e não apenas um projeto historicamente condicionado. Ainda que seja possível pensarmos numa atitude diferente perante a natureza, disto não podemos deduzir um modelo alternativo de técnica ou de ciência.

Perante essa controvérsia, Habermas procura enquadrar a questão num outro sistema de referências a fim de reformular a noção de "racionalização" de Weber, bem como discutir a crítica que Marcuse dirige àquele.

O novo direcionamento que Habermas tenta propor parte fundamentalmente da diferença entre "trabalho" e "interação". Por "trabalho" Habermas entende tanto a ação instrumental, orientada por regras técnicas, como a escolha racional, que se orienta por estratégias. Trata-se aqui do processo que envolve a realização de fins a partir de condições dadas, processo que se dá sob a organização dos meios adequados e de uma valoração estratégica em vista de um eficiente controle sobre a realidade. 
Já a "interação" assinalada por Habermas refere-se a "ação comunicativa", uma interação simbolicamente mediada, e o "seu sentido objetiva-se na comunicação lingüística quotidiana" (HABERMAS, 1968). Tal interação tem como critério de orientação regras entendidas e reconhecidas pelos agentes. O agir comunicativo se funda na intersubjetividade e já se estabelece desde que haja dois sujeitos em interação, e desde que eles se reconheçam como tais, compartilhando as mesmas regras no discurso. Há nessa categoria, portanto, uma fundamentação intersubjetiva e racional de normas que funcionam como pressupostos da linguagem e da intercompreensão.

O processo de "racionalização" que se encontra sob discussão refere-se à passagem de um modelo de sociedade "tradicional" para uma sociedade "moderna", entendendo-se aqui como "moderna" a sociedade tardo-capitalista na qual se solidifica um sistema econômico-produtivo que funciona de modo regular e que permite a expansão da produção. Antes de tal modelo o que havia era um modo de produção pré-capitalista amparado numa técnica pré-industrial e numa ciência pré-moderna. Na medida em que ocorre a passagem de um modelo de sociedade para o outro, se modifica também a forma de se legitimar a dominação.

$\mathrm{Na}$ sociedade tradicional as tradições culturais exerciam uma enorme força enquanto base de legitimação. Segundo Habermas, isto se modifica quando na sociedade moderna as inovações tecnológicas passam a ser cada vez mais presentes. A institucionalização da inovação enquanto tal (novas tecnologias, novas estratégias, etc.), que se dá no desenvolvimento do capitalismo, rompe com a inatacabilidade dos critérios legitimadores da sociedade tradicional. Nesse ponto, lembramos do diagnóstico feito por Lyotard em A condição pós-moderna, quando ele ressalta a perda do poder de legitimação dos “metarrelatos” (idealismo, marxismo.).

Com a inovação institucionalizada, a ciência e a técnica passam a preponderar como critérios (aparentemente neutros) de legitimação, “abalando assim a 'superioridade' tradicionalista do enquadramento institucional perante as forças produtivas" (HABERMAS, 1968). Se voltarmos à distinção estabelecida anteriormente entre "interação" (ação comunicativa) e "trabalho" (ação instrumental) notaremos que esta última categoria passa a preponderar no enquadramento institucional da sociedade, já que nela identificamos a "racionalização", ou seja, a progressiva expansão dos mecanismos de regulação econômicos e políticos pautados na racionalidade instrumental, e na ação instrumental e estratégica.

É nesse quadro da sociedade moderna que a técnica e a ciência assumem um papel ideológico, pois como afirma Habermas: 
Só assim surgem as ideologias em sentido estrito: substituem as legitimações tradicionais da dominação, ao apresentarem-se com a pretensão da ciência moderna e ao justificaremse a partir da crítica às ideologias. As ideologias são coetâneas da crítica ideológica (HABERMAS, 1968).

Com base nesse diagnóstico, Habermas apresentará outra via para uma possível emancipação, diferente daquela pensada por Marcuse. O que Habermas tenta formular é uma forma de emancipação política que se contraponha, no sentido de romper com uma forma de ideologia de cunho tecnocrático, uma vez que nessa nova base de legitimação a política teria tornado-se mero jogo de estratégias para a resolução de questões técnicas, onde a "solução de tarefas técnicas não está referida à discussão pública" (HABERMAS, 1968). Nesse sentido, passaríamos por um amplo processo de despolitização, engendrado e encoberto pela institucionalização da tecno-ciência como ideologia, que afasta a autocompreensão da sociedade no âmbito da ação comunicativa ao substituí-la pelas categorias da ação racional dirigida a fins, baseadas num modelo "científico". Assim:

a ideologia de fundo, um tanto vítrea, hoje dominante, que faz da ciência um feitiço, é mais irresistível e de maior alcance do que as ideologias de tipo antigo, já que com a dissimulação das questões não só justifica o interesse parcial de dominação por parte de outra classe, mas também afeta o interesse emancipador como tal do gênero humano. (HABERMAS, 1968)

Essa nova configuração ideológica leva ao que Habermas chama de "latência das oposições de classe". O conceito de "luta de classes" formulado por Marx não seria mais aplicável de forma apropriada ao novo contexto, e, portanto, não alcançaria o efeito emancipatório almejado. Contribui para isso o fato de que:

O sistema capitalista tardio está a tal ponto determinado por uma política de compensações que assegura a lealdade das massas dependentes do trabalho, ou seja, por uma política de evitação do conflito, que é precisamente esse conflito incrustado sem cessar na estrutura da sociedade com a regularização do capital em termos de economia privada, o que com a maior probabilidade irá permanecer latente. (HABERMAS, 1968)

O foco de Habermas é o impacto negativo que essa ideologia faz recair sobre o âmbito da comunicação e da linguagem comuns. A socialização e o papel de uma intersubjetividade da compreensão seriam, segundo Habermas, diretamente afetados pela desmesurada ampliação do poder de disposição técnica, o que impediria o estabelecimento de uma comunicação emancipada.

É manifesto, portanto, que Habermas aposta numa "racionalização" que se opere no âmbito da comunicação, uma racionalidade não voltada para fins técnicos e de dominação, mas que tenha como base o agir comunicativo; voltado diretamente para a discussão pública e que 
oferece recursos para a participação autônoma e efetiva dos agentes sociais. Tornar-se-ia possível uma plena autonomia dos indivíduos na medida em que se rompessem as amarras de uma racionalidade estritamente técnica e passássemos a uma discussão em torno dos princípios e das normas orientadoras da ação, sem estratégias de manipulação ou dominação. Antes, o que se requer nesse processo é o entendimento mútuo, assentado sobre convicções comuns dos agentes em interação, pois como afirma Habermas, os atos do entendimento mútuo "que vinculam os planos de ação dos diferentes participantes e reúnem as ações dirigidas para objetivos numa conexão interativa, não precisam de sua parte ser reduzidos ao agir teleológico" (HABERMAS, 1989). Tratase, portanto, de um racionalidade não instrumental, ou técnica, mas prática, voltada para o que Habermas chama de "mundo da vida", uma racionalidade que se daria por meio da comunicação aberta:

em todos os níveis dos processos políticos e dos processos novamente politizados de formação da vontade (...) dotaria os membros da sociedade com oportunidades de uma mais ampla emancipação e de uma progressiva individuação. (HABERMAS, 1968)

A "teoria do agir comunicativo" e a noção de "mundo da vida" mereceriam ser aprofundadas em um outro trabalho. Aqui, cabe apenas salientar que esses itens do pensamento habermasiano parecem constituir uma proposta de emancipação que supostamente escaparia à dominação que o aparato técnico-científico exerce quando este se insere no âmbito da vida política e de modo violento converte todos os agentes e processos políticos em peças de um esquema dirigido a fins. Habermas vê na teoria da ação comunicativa não só um recurso de linguagem que poderia servir no exercício da compreensão mútua, mas uma forma de prática social que estaria ao alcance de qualquer agente político, uma vez que é indissociável do mundo da vida. Assim:

A razão operante na ação comunicativa não se encontra apenas sob as limitações, por assim dizer, situacionais e exteriores; suas próprias condições de possibilidade obrigamna a ramificar-se nas dimensões do tempo histórico, do espaço social e das experiências centradas no corpo. O potencial racional do discurso é entretecido com os recursos de um mundo da vida sempre particular. (HABERMAS, 2000)

Habermas considera a razão comunicativa como uma ação traz consigo o potencial emancipador que se almejava desde a modernidade. Nela encontraríamos de fato um canal para o "uso público da razão", para a autonomia pretendida desde o iluminismo, e a qual a "pósmodernidade" parece ter esquecido ou precocemente declarado fracassada. As estruturas do mundo da vida se efetivam e se reproduzem por via da ação orientada ao entendimento, assim, segundo Habermas, é perfeitamente possível, com base na ação comunicativa, uma liberação sucessiva do potencial da razão. 


\section{CONSIDERAÇÕES FINAIS}

Como pudemos notar, tanto Lyotard quanto Habermas identificam uma série de mudanças que se operam ainda na estrutura sócio-política contemporânea. No que diz respeito ao estatuto do saber, da pesquisa e da produção científica, bem como da forma com que se legitima tal produção e sua objetivação no mundo da vida, isto é, no mundo das relações sociais comuns, ambos os filósofos reconhecem que certos (grandes) ideais da modernidade não exercem mais o mesmo impacto, de modo que o "projeto" da modernidade, que se considerava potencialmente emancipador, parece ter se dissolvido. Na visão de Lyotard, o ambiente "paralógico" no qual nos encontramos não nos dá qualquer sinal de estabilidade, mas unicamente continua seu funcionamento tendo como parâmetro a otimização dos resultados e a busca por uma crescente eficiência na produção distribuição e aplicação do saber. Além do que, a pragmática social seria composta por um emaranhado heteromorfo de jogos de linguagem, o que impossibilitaria o alcance de um consenso universalmente válido. Já Habermas insiste na defesa de uma emancipação nos moldes modernos através da razão comunicativa, dado que para ele a modernidade é um projeto ainda em vias de efetivação.

\section{Referências bibliográficas}

HABERMAS, J. Consciência moral e agir comunicativo. Trad. Guido A. de Almeida. Rio de Janeiro: Tempo Brasileiro, 1989.

O discurso filosófico da modernidade. Trad. Luiz Sérgio R. R. Nascimento. São Paulo: Martins Fontes, 2000.

Técnica e Ciência como Ideologia. Trad. Artur Morão. Lisboa: Edições 70, 1968.

LYOTARD, Jean-François. A condição pós-moderna. Trad. Ricardo C. Barbosa; Posfácio: Silviano Santiago. 12 ed. Rio de Janeiro: José Olympio, 2009 